\title{
JOURNAL.RU
}

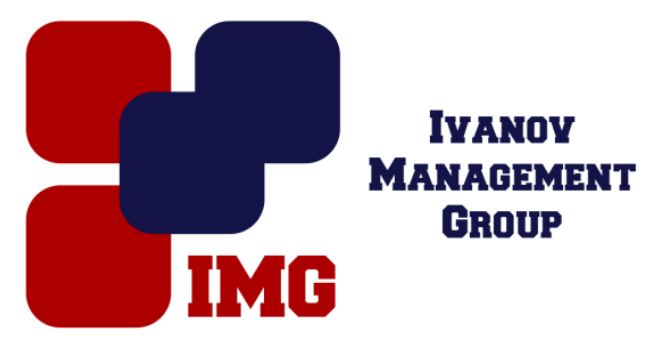

Первеев М.В., Шуйкова И.А., Авдеева И.О.

ГОБОУ «Центр поддержки одаренных детей «Стратегия»

Липеик, Россия

doi: 10.18411/lj-30-06-2017-16

idsp 000001:1j-30-06-2017-16

\section{Методы стимулирования участников дистанционного образовательного проекта младшей возрастной группы}

\section{Аннотация}

Продолжением аудиторного обучения с учителем, в настоящее время, является дистанционное обучение, организация которого возможна, в частности, при помощи дистанционных образовательных порталов. Методы онлайн обучения, как и методы классического обучения, становятся успешными при наличии высокой мотивации учащихся. Грамотное построение системы стимулирования, особенно в процессе дистанционного обучения, позволяет сохранить длительный интерес обучающихся к предмету или прохождению электронного курса, повысить мотивацию и получить на выходе необходимый высокий уровень результативности. В статье описываются как уже апробированные методы стимулирования, так и предложенные к внедрению в систему дистанционного образовательного портала ZimaLip.ru[1].

Ключевые слова: дистанционное обучение, методы стимулирования, мотивация к учебной деятельности, соревновательные ранговые системы стимулирования.

Авторским коллективом был разработан и апробирован в течение года дистанционный образовательный портал ZimaLip.ru (Заочная информационноматематическая академия липецких школьнков), ориентированный на школьников 3-6 классов, имеющих мотивацию к изучению математики и информатики. Портал предоставляет всем желающим школьникам возможность 
участия в олимпиадных турах, которые проходят дважды в месяц на протяжении всего календарного года, а также поддержку в виде теоретических конспектов и рекомендаций преподавателей. Цель деятельности портала в рамках концепции развития математического образования в РФ предполагает вовлечение в дополнительную информационно-математическую образовательную среду младших школьников, их родителей, учителей; повышение интереса учащихся к предметам информационно-математического цикла.

С целью анализа контингента портала ZimaLip.ruпо окончании его первого года работы был проведен кластерный анализ, в результате которого учащиеся были распределены по четырём группам. Первая группа школьников «Активные новички». Это недавно зарегистрировавшиеся пользователи, активно решающие задачи. Вторая группа - «Случайные пользователи», представляет собой школьников, которые зарегистрировались не очень давно, но не проявляют активность. Третья группа -«Звезды» - давние участники, стабильно и активно решающие задачи. Четвёртая группа - «Лентяи»-зарегистрировались в самом начале работы портала и время от времени проявляющие активность. Кластерный анализ показал, что группа «лентяев» и «случайных пользователей» довольно многочисленная. Среди причин отказа школьников от участия в проекте, снижения их активности, можно назвать: «индивидуальную» трудность заданий, не коррелирующую с уровнем математической подготовки каждого конкретного ребенка; не достаточно гибкие подходы к стимулированию пользователей. Удержание таких школьников с сохранением у них интереса к предмету возможно при помощи внедрения разнообразных методов стимулирования, в частности, используя адаптивные системы обучения, соревновательные ранговые системы стимулирования, методы вербального оценивания.

В процессе создания портала для мотивации потенциальных учеников была введена соревновательная ранговая система стимулирования (СРСС) [2], в которой было задано число классов (уровней стимулирования), а также величина поощрений агентов (учеников), попавших в тот или иной класс. За каждую правильно и вовремя решенную задачу ученик получает 1 балл (1 «снежинку»). В качестве числа уровней было выбрано $n=10$ - количество уровней оценивания школьников. Множество баллов $A=\left[0 ; A^{+}\right] \subseteq \mathrm{R}^{\prime}$ было разбито на $n=10$ отрезков (уровней) $\left[Y_{i} ; Y_{i+1}\right], i=0, \ldots, n-1, Y_{0}=0, Y_{n}=$ $A^{+} . A=[0 ; 300]$ - максимально-возможное количество баллов, которое ученик может набрать примерно за 3 года стабильной работы. Деление на уровни 
множества баллов было проведено неравномерно с целью дополнительного мотивирования учеников в самом начале обучения (1, 2, 3 уровни) и более сознательного отношения к процессу обучения ближе к окончанию обучения $(9$, 10 уровни). Для того чтобы соотнести уровни обучения с некоторыми графическими характеристиками были выбраны цветовые отличия. Примеры уровней, их баллы и цветовые характеристики приведены на рисунке 1.

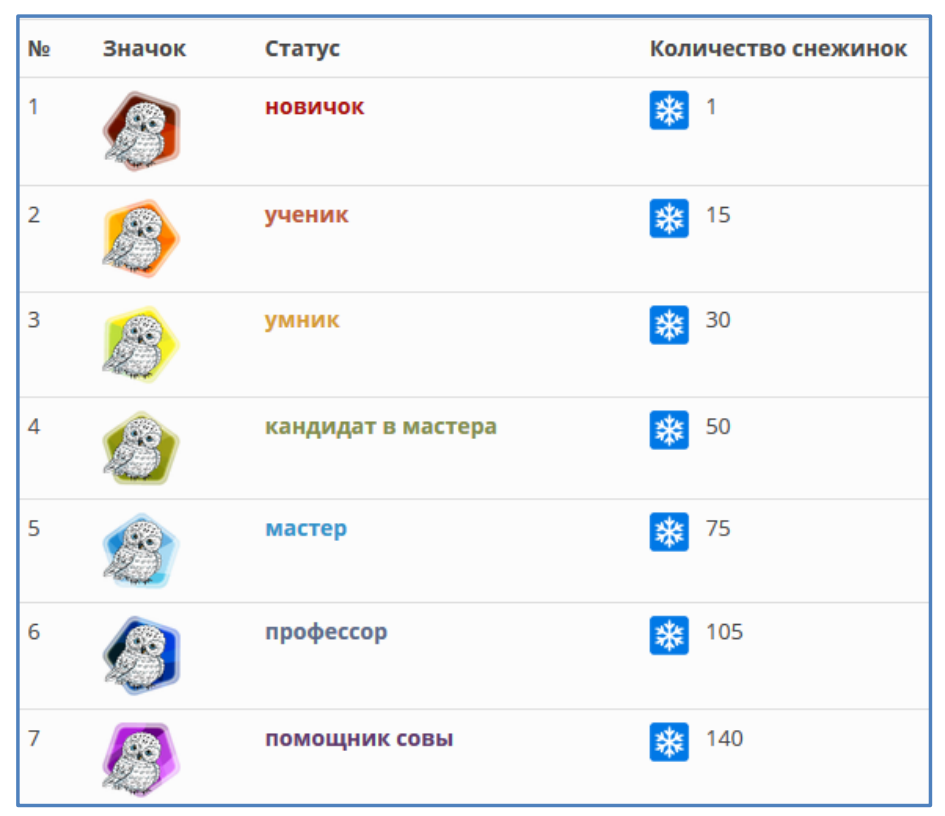

Рис. 1. Примеры уровней СРСС портала

Авторами предлагается переход системы стимулирования портала на балльную систему, которая должна удовлетворять соотношению: $q_{I}=$ $k \frac{A^{+}}{n} c_{I}, q_{i}=q_{i-1}+\left[c_{i} k\left(\frac{A^{+} i}{n}\right)-c_{i} k\left(\frac{A^{+}(i-1)}{n}\right)\right], i=2, \ldots, n$, где $k-$ нормировочный коэффициент, $c_{i}-$ производительность обучающегося, выражающаяся во времени, затраченном на решение каждого конкретного задания.В этом случае можно будет учесть производительность обучающегося, отражающую стабильность работы школьника. Таким образом, функцией стимулирования будет являться зависимость достигнутого школьником уровня обучения от заработанных баллов, которые в свою очередь были получены в результате правильно и вовремя выполненных заданий с оптимальной производительностью. Место в общей рейтинговой таблице показывает достигнутыйуровень обучения.

В рамках предлагаемой модели дистанционного обучения необходимы адаптивные технологии, выражающиеся в индивидуальном подборе заданий, в зависимости от достигнутого уровня обучения и успешности выполнения предыдущих заданий[3]. С помощью этой технологии у обучающихся 
поддерживается интерес и мотивация, а в самой модели исключается однотипность заданий и монотонность процесса обучения. Процесс управления адаптивным контролем знаний можно представить, как процесс управления сложной системой. Модель состоит из блоков: ученик, формировщик вопросов и задач, база знаний и база данных, алгоритм контроля, модель ученика. Блок «Модель ученика» отвечает за сбор информации об обучающемся, например, предыстории обучения, общем числе правильно выполненных заданий и производительности процесса решения задач. Опишем работу схемы. Ученик выполняет задание, алгоритм контроля оценивает правильность ответа и учитывает достигнутый на данный момент уровень обучения, затем определяет уровень сложности следующего задания. База данных подбирает под этот уровень сложности задачу и выдает ее ученику. Из вышесказанного следует, что алгоритм отбора и выдачи заданий основан на принципе обратной связи. Верный ответ предполагает усложнение последующего задания, неверный упрощение. Для реализации подобного алгоритма можно использоватьпараметрическую модель Раша.

Модель Раша предполагает, что вероятность $P_{i j}$ правильного ответа -го обучающегося на $\square$-ое задание определяется разностью логитов (латентных параметров): $\theta_{i}$ - достигнутый уровень обучения и $\delta_{i}-$ трудность предложенного задания. $P_{i j}=\frac{1}{1+\exp \left(-1.73\left(\theta_{i}-\delta_{i}\right)\right)}$.

Для повышения мотивации участников образовательного процесса предусмотрены вербальные оценки учеников. Для генерации базы таких оценок были использованы алгоритмы дистрибутивной семантики, а в частности инструмент Word2Vec. Данный инструмент представляет слова в виде векторов, что позволяет легко оценивать семантическую близость между словами. Для этого нужно вычислить косинусную близость между векторами, которые соответствуют интересующим нас словам:

$$
\cos \left(w_{1}, w_{2}\right)=\frac{\vec{V}\left(w_{1}\right) \times \vec{V}\left(w_{2}\right)}{\left|\vec{V}\left(w_{1}\right)\right| \times\left|\vec{V}\left(w_{2}\right)\right|} .
$$

Данный метод был использован для поиска синонимов к заданным прототипам вербальных оценок, что позволило сгенерировать достаточно обширную базу вербальных оценок.

Внедрение адаптивной системы обучения в модель работы порталаZimaLip.ru, улучшение системы генерации вербальных оценок учеников 
на основе алгоритмов дистрибутивной семантики, позволит повысить привлекательность портала, будет способствовать результативности обучения.

1. Дистанционный образовательный портал «Заочная информационно-математическая академия липецких школьников» http://zimalip.ru/ (дата обращения: 18.06.2017)

2. НовиковД.А.Механизмы стимулирования в организационных системах. М.: ИПУ РАН (научное издание), 2003.- 147 с.

3. Власенко А.А. Разработка адаптивной системы дистанционного обучения в сфере информационных технологий. - Воронеж. ВГУ (диссертация), 2014. 